JGG 2022;70:113-119

doi: $10.36150 / 2499-6564-N 474$

\title{
The GLP-1 receptor agonist Exendin-4 modulates hippocampal NMDA-receptor signalling in aged rats and improves cognitive impairment in diabetic elderly patients
}

\author{
Antonino Davide Romano ${ }^{1}$, Rosanna Villani ${ }^{1}$, Moris Sangineto ${ }^{1}$, \\ Tommaso Cassano ${ }^{2}$, Gaetano Serviddio ${ }^{1}$ \\ ${ }^{1}$ C.U.R.E. (University Center for Liver Disease Research and Treatment), Liver Unit, Department of \\ Medical and Surgical Sciences, University of Foggia, Foggia, Italy; ${ }^{2}$ Department of Medical and \\ Surgical Sciences, University of Foggia, Foggia, Italy
}

Glucagon-like peptide-1 agonists (GLP-1A) are revolutionary drugs for the treatment of type 2 diabetes mellitus. Exendin- 4 is an incretin agonist which shares $53 \%$ of GLP-1 amino-acid sequence and beyond its efficacy as antidiabetic, several studies demonstrated a neuroprotective effect in brain damage. NMDA receptor (NMDAR) is involved in memory formation processes and cognitive dysfunction. Herein, we wanted to explore whether Exendin-4 directly affected NMDA-R signal transduction pathway. We also evaluated clinical efficacy in ameliorating cognitive dysfunction. 18-months old Wistar rats were challenged for 30 days with intraperitoneal Exendin-4 or salt solution injection. Notably, in hippocampus Exendin-4 downregulated the gene expression of NMDA-R2A and 2B subunits, while significantly increased the NMDA-R2B phosphorylation. The clinical analysis of diabetic old patients revealed a significant improvement of cognitive dysfunction as demonstrated by the considerable increase in Mini Mental State Examination over time. Moreover, this improvement was not related to the glycaemic control. In conclusion, the GLP-1 agonist Exendin-4 ameliorated the cognitive performance of diabetic elderly patients and one suggested mechanism relies in the modulation of NDMAR-mediated glutamatergic signaling.

Key words: cognitive impairment, diabetes, GLP1, Exendin-4, NMDA, MMSE, Hippocampus

\section{INTRODUCTION}

Diabetes mellitus (DM), one of the most prevalent chronic diseases in the elderly, currently affects about $15 \%$ of 80 years old people, being a considerable health care burden ${ }^{1}$. DM complications encompass a wide spectrum of conditions such as heart attack, legs gangrene, renal failure, vision loss, autonomic and peripheral neuropathy, cerebrovascular disease, mostly due to micro- and macro-vascular degeneration ${ }^{2}$.

A growing body of evidence supports the hypothesis that diabetes affects the central nervous system (CNS), thus leading to the development of diabetic encephalopathy and other neurological co-morbidities. Moreover, cognitive dysfunction and dementia are typical DM complications,

\footnotetext{
This is an open access article distributed in accor dance with the CC-BY-NC-ND (Creative Commons Attribution-NonCommercial-NoDerivatives 4.0 International) license. The article can be used by giving appropriate credit and mentioning the license, but only for non-commercial purposes and only in the original version. For further information: https://creati-

vecommons.org/licenses/by-nc-nd/4.0/deed.en

Copyright by Società Italiana

di Gerontologia e Geriatria (SIGG) (c) (i) () $\ominus$

$$
\text { OPEN ACCESS }
$$
}

Received: October 20, 2021

\section{Moris Sangineto \\ C.U.R.E. (University Center for Liver Disease of Medical and Surgical Sciences, University .}

How to cite this article: Romano receptor agonist Exendin-4 mosignalling in aged rats and improves Geriatrics 2022;70:113-119. https://doi. 
which are often underdiagnosed and underestimated by health care workers. Cognition is a collective term to indicate superior brain functions, including memory, discernment, language, and analysis. Neuropsychological tests in diabetic patients typically show impairment of psychomotor efficiency, global cognition, episodic memory, semantic memory, and working memory ${ }^{3,4}$. Accordingly, the Rotterdam study demonstrated that $\mathrm{DM}$ is a risk factor for Alzheimer's disease (AD) ${ }^{5}$.

Moreover, recent studies reported the importance of glutamatergic transmission imbalance in the brain of diabetic patients and in animal models ${ }^{6,7}$. L-Glutamic acid (glutamate) is the most prevalent excitatory neurotransmitter in the vertebrate nervous system ${ }^{8}$. The ionotropic receptors of glutamate are distinguished by the selective agonists originally identified: the N-methyl-D-aspartate (NMDA), the kainic acid (KA) and the a-amino-3-hydroxy-5-methyl-4-isoxazolepropionic acid (AMPA) ${ }^{9}$. The NMDA receptor (NMDA-R) is involved in processes related to memory formation. Induction of memory long term potentiation (LTP) in the hippocampus requires agonistic activity on NMDA-R, while antagonists impair learning and memory capabilities ${ }^{10}$. Recently, it has been demonstrated that the downregulation of NMDA-R subunits is related to learning and memory disturbance in an animal model of neuropsychiatric systemic lupus erythematosus ${ }^{11}$. On the contrary, extracellular glutamate accumulation leads to an over-stimulation of glutamate receptors, including NMDA, hesitating in neurotoxicity ${ }^{12}$.

Glucagon-like peptide-1 (GLP-1) is an incretin, a metabolic hormone produced by the intestine, that increases insulin and decreases glucagon secretion in response to nutrient intake ${ }^{13,14}$. It has been reported that GLP1 receptors (GLP-1R) are expressed in human brain neurons, where they exert several functions, such as facilitating both hippocampal and synaptic plasticity, cognition and cell survival ${ }^{15}$. Accordingly, animal studies demonstrated that GLP1 influences learning and memory ${ }^{16-18}$. Other potential beneficial effects include amelioration of neurogenesis, reduction of inflammatory response and improvement of cognitive impairment, suggesting a protective effect against CNS-injuries ${ }^{19}$. Exendin-4 (Exe-4) is an incretin agonist which shares $53 \%$ of GLP-1 amino-acid sequence and is a drug approved for the treatment of type-2 DM (DM2). Similarly to GLP-1, Exendin-4 has a short half-life and is finally degraded by dipeptidyl peptidase-4 (DPP4) ${ }^{20}$. Beyond the incontrovertible efficacy as antidiabetic, some studies have suggested that Exendin-4 is protective against brain damage ${ }^{21,22}$.

Considering the high prevalence of cognitive dysfunction and the impairment in glutamatergic transmission in diabetic patients, we investigated whether a novel treatment like Exe-4 could directly impact on NMDA-R activity. To do this, we investigated the hippocampus NMDA-R activation after Exe-4 administration in aged rats, and we retrospectively analysed the cognitive function change of DM2 elderly patients one year after Exendin-4 therapy.

\section{METHODS}

\section{ANIMAL EXPERIMENT}

Forty male Wistar rats (Harlan, S. Pietro al Natisone, Udine, Italy), 18 months old, were caged in a temperature and light controlled environment, with free access to food and water and randomly divided into two groups: animals treated by intraperitoneal (ip) Exendin-4 (Exe4); and animals treated with vehicle only (controls).

All rats received care in compliance with the Principles of Laboratory Animal Care formulated by the National Society for Medical Research and the Guide for the Care and Use of Laboratory Animals, prepared by the Institute of Laboratory Animal Resources, published by the National Institutes of Health (NIH Publication No. 86-23, revised 1985), as well as in compliance with Italian laws on animal experimentation. Animals were sacrificed by intraperitoneal overdose of fentanyl and diazepam.

Control rats received only vehicle (citrate buffer), while Exe-4 group received $10 \mu \mathrm{m} / \mathrm{kg}$ Exe-4 (supplied by AstraZeneca Italia) intraperitoneally once a day for 30 days. Thirty days after, animals were sacrificed by intraperitoneal anesthetic overdose; subsequently, the brain was quickly removed, the hippocampus was isolated and immediately frozen in liquid nitrogen.

\section{ANALYSIS OF PROTEIN AND MRNA EXPRESSION}

\section{Immunoprecipitation and western blot analysis}

Hippocampus was homogenized in solubilization buffer containing Hepes $10 \mathrm{mM}$ (ph 7.4), NaCl $137 \mathrm{mM}, \mathrm{KCl}$ $4.6 \mathrm{mM}, \mathrm{KH} 2 \mathrm{PO} 41.1 \mathrm{mM}, \mathrm{MgSO} 40.6 \mathrm{mM}$ and protease inhibitor; the samples were centrifuged for 10' at $14,000 \mathrm{~g}$ then per 10' and the supernatants stored at $-80^{\circ} \mathrm{C}$ until the analysis ${ }^{23}$. Proteins were immunoprecipitated at $4^{\circ} \mathrm{C}$ overnight with anti-NMDA-2A (Rabbit polyclonal, from Cell Signaling Technology Inc., 3 Trask Lane, Danvers, MA 01923, USA) or anti-NMDA-2B antibody (Rabbit polyclonal, from Santa Cruz Biotechnology Inc, Santa Cruz, California, USA) and $100 \mu$ protein G-Agarose beads, using the Protein G Immunoprecipitation Kit (IP-50, Sigma-Aldrich, Saint Louis, Missouri, USA). The immunoprecipitated samples were loaded on 6\% SDS-PAGE gel and transferred to nitrocellulose membrane for immunoblot analysis with anti-NMDA-2A 
and NMDA-2B antibodies. Optical density values were normalized against beta-actin expression; reactive bands were visualized by the enhanced chemiluminescence method by VersaDoc Image System (Bio-Rad Laboratories Headquarter, Hercules, California, USA).

\section{RNA extraction and Real-Time Polymerase Chain Reaction (rt-PCR) analysis}

Isolated hippocampi stored at $-80^{\circ} \mathrm{C}$ were homogenized and total RNA was isolated using TRIzol ${ }^{\circledR}$ Reagent (Invitrogen) as indicated by the manufacturer protocol. c-DNA was obtained using a random hexamer primer and a Super Script III Reverse Transcriptase kit, as described by the manufacturer (Invitrogen, Frederick, Maryland, USA).Specific primers (rat NMDA-2A: forward, 5'- CAGTGATGTGTATATTTCAGAGC-3'; reverse, 5'- ACACTCGTCTATTGCTGCAG -3'; rat NMDA-2B: forward, 5'- TCCGTCTTTCTTATGTGGATATGC-3'; reverse, 5'- CCTCTAGGCGGACAGATTAAGG-3') were added, along with iQ SYBER Green Supermix (Bio Rad) for Real-time quantization by using a i-Cycler detection system (Bio-Rad Laboratories Headquarter, Hercules, California, USA). The cycle threshold (CT) was determined, and the relative gene expression was subsequently calculated with $\triangle \triangle C T$ method.

Human study

In January 2021 we retrospectively collected data of all patients coming in the previous year at the outpatient service of the Department of Medical and Surgical Sciences, School of Geriatrics, University of Foggia, Italy. We identified individuals older than 70 years, affected by type 2 diabetes, receiving combination therapy with a GLP1-R agonist (exenatide, exenatide long-acting release) and other oral antidiabetics (sulfonylureas, glinides, thiazolidinediones, biguanides) and who completed the Mini Mental State Examination (MMSE) at baseline (T0), after 6 months of Exe-4 therapy (T6) and 12 months therapy (T12). MMSE score are adjusted according to age and education, as assessed for the Italian population ${ }^{24}$.The hospital's Ethics Committee approved the study protocol, and patient anonymity was preserved. To avoid misunderstanding on cognitive ability derived from hyperglycemia or decompensated diabetes, patients with a $\mathrm{HbA} 1 \mathrm{c}>8 \%$ at the first visit were excluded. We identified 138 patients who met such criteria. Patients reporting history of psychiatric disease, active cancer, alcohol dependence, dysthyroidism, an established diagnosis of dementia or a memory disorder were exclusion criteria.

\section{STATISTICAL ANALYSIS}

Data were expressed as mean \pm standard deviations of the mean (SDM). Differences among means were analyzed using unpaired t-test. One-way ANOVA was used to analyze difference between three groups and Bonferroni multiple comparison test was applied as a post hoc test. Shapiro-Wilk test was applied to verify the normal distribution of the variables and Spearman correlation test was used to explore correlation between normal distributed variables. $P<0.05$ was accepted as the lowest level of significance. The package GraphPad Prism 7 for Windows (GraphPad Software Inc., San Diego, CA, USA) and Statistical Package for Social Sciences (v. 15.0) were used to perform all statistical analysis and graphs.

\section{RESULTS}

\section{EXENDIN-4 DOWN-REGULATES HIPPOCAMPAL NMDA-R2B MRNA EXPRESSION}

GLP1 exerts beneficial effects on CNS, most notably the hippocampus, protecting neurons against amyloid-beta peptide accumulation ${ }^{25}$. Here, we explored the mRNA expression of rat-hippocampal NMDA-R2A/B, two glutamate receptor subunits highly expressed in hippocampus. Notably, Exe-4 administration significantly down-regulated NMDA-R2A and -2B expression compared to control rats (Fig. 1).

\section{EXENDIN-4 INDUCES NMDA-R2B PHOSPHORYLATION}

To clarify whether the gene expression profile was related to the receptor activity, we tested the degree of NMDA-R activation by quantifying its tyrosine phosphorylation. Interestingly, the western blot (WB) analysis indicated a significant increase of tyrosine phosphorylated NMDA-2B subunit after one-month treatment

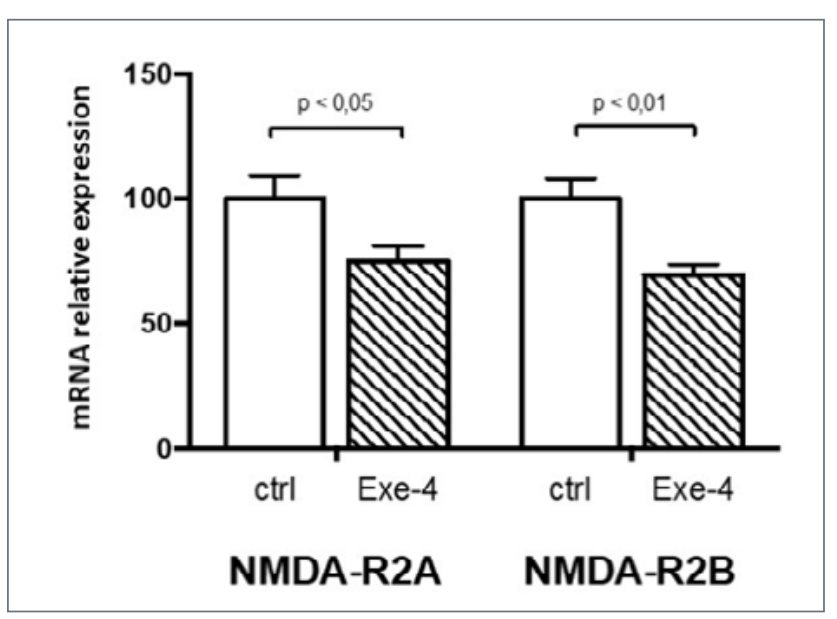

Figure 1. Effect of Exendin-4 stimulation on the hippocampus NMDA-R2A/B gene expression. NMDA-R2A and NMDA-R2B mRNA expression fold over control rats, measured by qPCR. Data are shown as percent \pm SD. P values refer to the results of the unpaired Student's T test. 


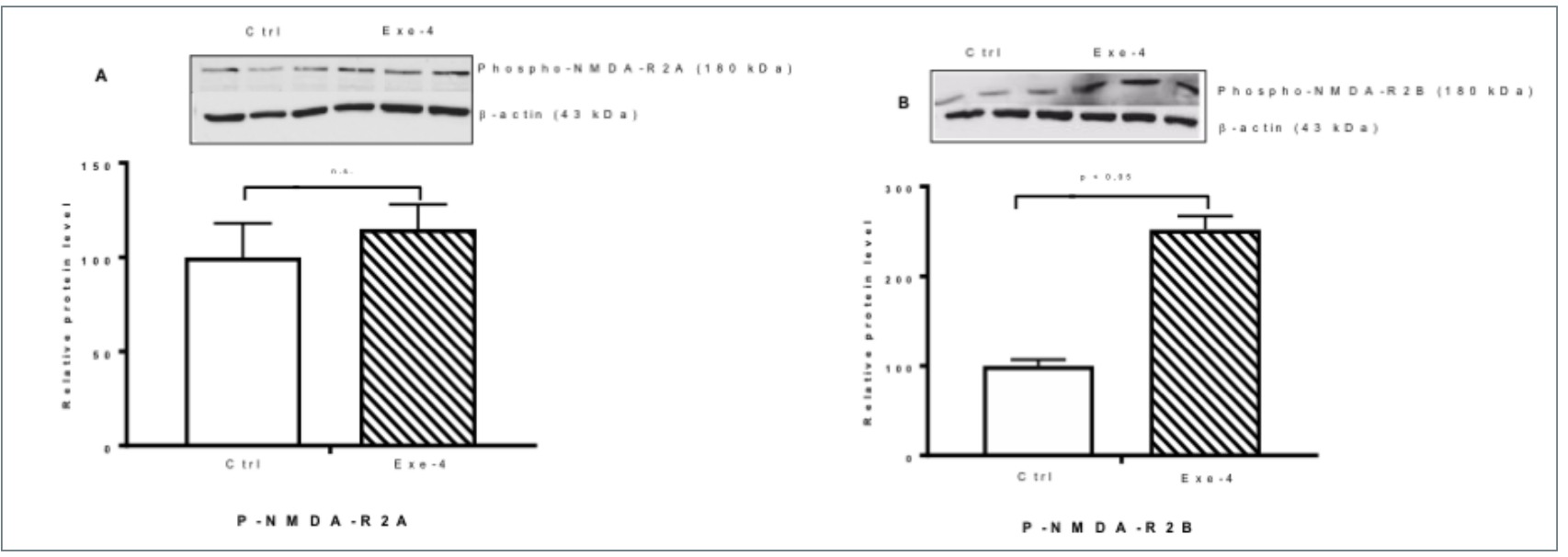

Figure 2. Western blot analysis of NMDA-2A and NMDA-2B phosphorylation in control and Exendin-4 treated rats. Densitometry data from Western blots are shown together with representative experimental images and normalized against Beta-actin; data are expressed as mean \pm SD and fold over control rats; P values refer to the results of the unpaired Student's T test.

with Exe-4 (Fig. 2B). Whilst, only a non-significant increase was observed in NMDA-R2A phosphorylation levels (Fig. 2A).

Therefore, one-month Exe-4 administration positively modulated the activity of NMDA-R in hippocampal tissue, probably reducing the mRNA expression for a negative feedback.

\section{IMPACT OF EXENDIN-4 ON COGNITIVE FUNCTIONS IN ELDERLY DIABETIC PATIENTS}

Demographic parameters and the use of antidiabetic drugs are indicated in Table I. Of notice, study population was overweight on average (BMI: $29.77 \pm 3.7$, IR: 22.536) and all the patients introduced Exe-4 as second line treatment (Tab. I).

MMSE for at least three visits (baseline, after 6 months and after 12 months) was performed to all 138 patients. To avoid confusion due to hyperglycaemia, we excluded patients with $\mathrm{HbA} 1 \mathrm{c}>8 \%(\mathrm{n}=11)$. After 6 months and 12 months of therapy the glycaemic control of the study population did not significantly changed as shown by HbA1c levels (Fig. 3).

Very interestingly, after Exe-4 treatment introduction the MMSE score significantly increased over the time,

Table I. Main characteristics of the patients included in the study.

\begin{tabular}{|c|c|c|c|}
\hline & $\mathbf{N}$ & Mean ( \pm SDM) & Interquartile range \\
\hline $\mathrm{N}$ of participants & 138 & & \\
\hline Age (years) & & $76 \pm 6.3$ & $70-88$ \\
\hline $\operatorname{Sex}(M / F)$ & $62 / 76$ & & \\
\hline Duration of diabetes (years) & & $18 \pm 8$ & $8-25$ \\
\hline $\mathrm{BMI}\left(\mathrm{kg} / \mathrm{m}^{2}\right)$ & & $29.77 \pm 3,7$ & $22.5-36$ \\
\hline Waist circumference $(\mathrm{cm})$ & & $91 \pm 7.8$ & $57-132$ \\
\hline \multicolumn{4}{|l|}{ Type of GLP1-Ra } \\
\hline & Exenatide & $41(29.7 \%)$ & \\
\hline & Exenatide LAR & $97(70.2 \%)$ & \\
\hline \multicolumn{4}{|c|}{ Use of concomitant diabetes drug } \\
\hline & Metformin & $117(84,7 \%)$ & \\
\hline & Sulfonylureas & $17(12,31 \%)$ & \\
\hline & Glinides & $6(4.34 \%)$ & \\
\hline & Thiazolidinediones & $9(6.52 \%)$ & \\
\hline & T0 & T6 & T12 \\
\hline MiniMental score & $20.82 \pm 2,8$ & $24.12 \pm 1,7$ & $25 \pm 2,1$ \\
\hline $\mathrm{HbA}_{1 \mathrm{c}}(\% \pm \mathrm{SDM})$ & $7.9 \pm 0.1$ & $7.2 \pm 0.8$ & $7.6 \pm 0.4$ \\
\hline
\end{tabular}




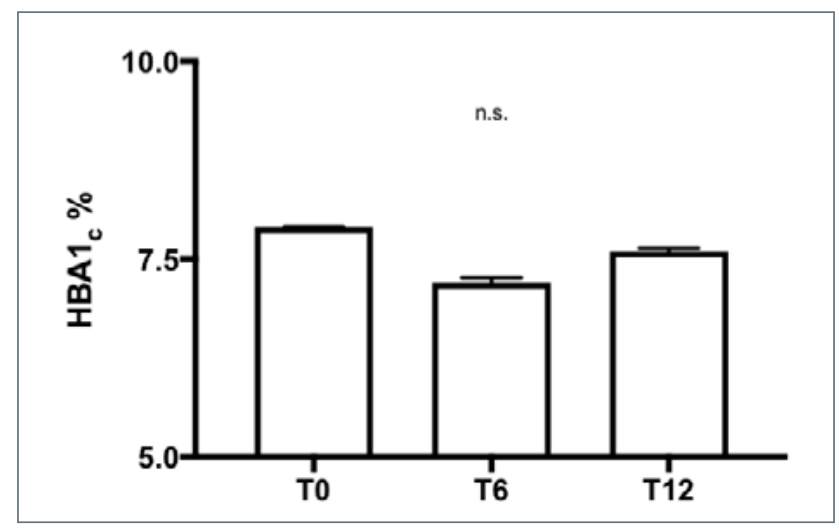

Figure 3. Change in glycated haemoglobin levels at baseline, T6 and T12 after Exendin-4 therapy; data are expressed as means \pm $\mathrm{SDM}$; P values refer to the results of ANOVA for repeated measures.

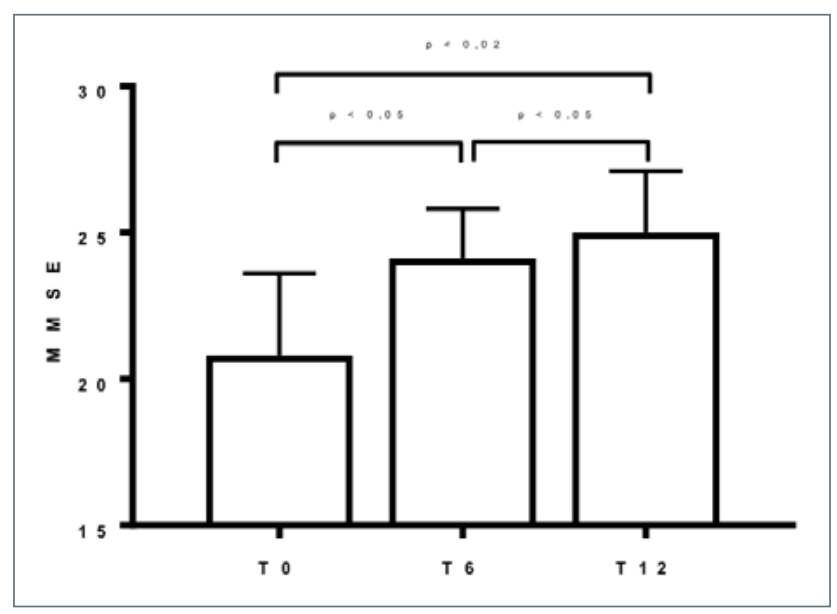

Figure 4. MMSE score of diabetic patient at baseline (T0), T6 and T12 after Exendin-4 introduction; data are expressed as means \pm SDM; $P$ values refer to the results of ANOVA for repeated measures and post-hoc analysis with Bonferroni's test for multiple comparisons.

indicating a progressive improvement of the cognitive function (Fig. 4).

In order to unequivocally exclude any type of influence between glycaemic balance and cognitive performance, we excluded the correlation between MMSE and $\mathrm{HbA} 1 \mathrm{c}$ along the observation time (Tab. II).

Overall, these data suggest that Exe-4 treatment improved the cognitive function of diabetic elderly patients independently of their glycemic control.

\section{DISCUSSION}

The maintenance of euglycemia is of crucial importance for diabetic patients. However, once chronic
Table II. Spearman correlation analysis testing the association between MMSE and glycated hemoglobin levels at baseline, T6 and T12 after Exendin-4 introduction.

\begin{tabular}{|l|c|c|}
\hline & $\mathbf{r}$ & $\mathbf{P}$ \\
\hline T0 & 0.20 & 0.3 \\
\hline T6 & 0.25 & 0.12 \\
\hline T12 & 0.34 & 0.16 \\
\hline
\end{tabular}

complications occur, the glycemic control may be not sufficient to treat these conditions. Accordingly, a substantial body of evidence has demonstrated the association between diabetes mellitus and the typical alterations of vascular dementia, and Alzheimer's disease ${ }^{3}$. Animal models suggest that cognitive impairment occurring in diabetes may be related to hippocampus alterations ${ }^{26-28}$. Glutamate receptors, NMDARs above all, are an excitatory receptors family, crucial in controlling hippocampus synapses long-term potentiation (LPT) during learning and memory formation ${ }^{29,30}$. Sun et al. ${ }^{31}$ demonstrated in vitro that insulin protects neurons directly via IR and PI3K/Akt activation pathway and indirectly, via synaptic activity-dependent stimulation of NMDA receptors. In the last few years, GLP1-R agonists have been introduced for the treatment of type 2 diabetes. Beyond the improvement of glucose metabolism, a neuroprotective effect of these drugs in animal models has been shown ${ }^{32}$. Recently, Valdini et al. ${ }^{33}$ demonstrated that Liraglutide, a GLP1-RA is effective in ameliorating cognitive function of diabetic patients. Other studies reported neuroprotective effects, although convincing mechanisms are not shown 18,21,22. Here, we used a novel GLP1-RA, Exendin-4, to explore its action on hippocampal NMDAR activity in aged rats and cognition effects in elderly diabetic patients. The treatment of rats with $10 \mu \mathrm{g} / \mathrm{kg} /$ day Exe-4 for onemonth provoked a down-regulation of NMDAR2A and -2B subunits gene expression, while the protein phosphorylation increased. Notably, it is shown that the hippocampal gene expression of NMDAR2B is enhanced in diabetic rats, facilitating the glutamate toxicity ${ }^{34}$. On the contrary, NMDAR2B phosphorylation governs hippocampal LTP and memory formation ${ }^{35}$ and, very importantly, protein levels of 2B phosphorylated subunit are significantly reduced in hippocampus of $A D$ patients ${ }^{6}$.

Here we showed that Exe-4 modulated hippocampal NMDAR phosphorylation and expression, probably improving neuronal plasticity and damage.

In accordance, in a diabetic population with 76 years mean age we observed a very important improvement of cognitive performance over time during Exe-4 treatment. This was independent of the glycemic control 
as the MMSE improvement was not associated with HBA1c levels, underlining that the achievement of euglycemia is often not relevant to treat diabetes chronic complications. Therefore, drugs with pleiotropic effects are needed in complicated diabetes.

In conclusion, diabetes therapy with the GLP-1 agonist Exe-4 improved cognitive impairment in elderly subjects, independently of glycemic control, and one potential mechanism lies in the modulation of NDMAR-mediated glutamatergic signaling.

\section{Ethical consideration}

All procedures involving human participants were conducted in accordance with the 1964 Helsinki Declaration and its later amendments. Informed consent was obtained from all subjects involved in the study.

\section{Acknowledgement}

None.

\section{Conflict of interest}

The Authors declare no conflict of interest.

\section{Funding}

This research did not receive any specific grant from funding agencies in the public, commercial, or not-forprofit sectors.

\section{Authors Contribution}

A.D.R. contributed to conception, design, data analysis and drafting the work; R.V. contributed to data collection and interpretation; M.S. contributed to data interpretation and work draft; T.C. and G.S. contributed to critical revision of the article.

\section{Informed Consent Statement}

Informed consent was obtained from all subjects involved in the study

\section{References}

1 Wild S, Roglic G, Green A, et al. Global prevalence of diabetes: estimates for the year 2000 and projections for 2030. Diabetes Care 2004;27:1047-1053. https://doi. org/10.2337/diacare.27.5.1047

2 Zhao Y, Ye W, Boye KS, et al. Prevalence of other diabetes-associated complications and comorbidities and its impact on health care charges among patients with diabetic neuropathy. J Diabetes Complications 2010;24:9-19. https://doi.org/10.1016/j.jdiacomp.2008.09.001

3 Arvanitakis Z, Wilson RS, Bienias JL, et al. Diabetes mellitus and risk of alzheimer disease and decline in cognitive function. Arch Neurology 2004;61:661. https://doi. org/10.1001/archneur.61.5.661
4 Ryan CM, Williams TM. Effects of insulin-dependent diabetes on learning and memory efficiency in adults. $J$ Clin Exp Neuropsychol 1993;15:685-700. https://doi. org/10.1080/01688639308402589

5 Ott A, Stolk RP, Hofman A, et al. Association of diabetes mellitus and dementia: the Rotterdam Study. Diabetologia 1996;39:1392-1397. https://doi.org/10.1007/ s001250050588

6 Sze C, Bi H, Kleinschmidt-DeMasters BK, et al. N-Methyl-D-aspartate receptor subunit proteins and their phosphorylation status are altered selectively in Alzheimer's disease. J Neurol Sci 2001;182:151-159. https://doi. org/10.1016/s0022-510x(00)00467-6

7 Anu J, Peeyush Kumar T, Nandhu MS, et al. Enhanced NMDAR1, NMDA2B and mGlu5 receptors gene expression in the cerebellum of insulin induced hypoglycaemic and streptozotocin induced diabetic rats. Eur $\mathrm{J}$ Pharmacol 2010;630:61-68. https://doi.org/10.1016/j. ejphar.2009.12.024

8 Fonnum F. Glutamate: a neurotransmitter in mammalian brain. J Neurochemistry 1984;42:1-11. https://doi. org/10.1111/j.1471-4159.1984.tb09689.x

9 Watkins JC, Korgsgaard-Larsen P, Honoré T. Structure-activity relationships in the development of excitatory ammo acid receptor agonists and competitive antagonists. Trends Pharmacol Sci 1990;11:25-33. https://doi. org/10.1016/0165-6147(90)90038-a

10 McDonald JW, Johnston MV. Physiological and pathophysiological roles of excitatory amino acids during central nervous system development. Brain Res Rev 1990;15:4170. https://doi.org/10.1016/0165-0173(90)90011-c

11 Luciano-Jaramillo J, Sandoval-Garcia F, Vazquez-Del Mercado $\mathrm{M}$, et al. Downregulation of hippocampal NR2A/2B subunits related to cognitive impairment in a pristane-induced lupus BALB/c mice. PLoS One 2019;14:e0217190. https://doi.org/10.1371/journal.pone.0217190

12 Zanotto C, Hansen F, Galland F, et al. Glutamatergic alterations in STZ-induced diabetic rats are reversed by Exendin-4. Mol Neurobiol 2019;56:3538-3551. https://doi. org/10.1007/s12035-018-1320-5

13 Batista AF, Forny-Germano L, Clarke JR, et al. The diabetes drug liraglutide reverses cognitive impairment in mice and attenuates insulin receptor and synaptic pathology in a non-human primate model of Alzheimer's disease. J Pathol 2018;245:85-100. https://doi.org/10.1002/path.5056

14 Nauck MA, Meier JJ. Incretin hormones: their role in health and disease. Diabetes Obes Metab 2018;20(Suppl 1):521. https://doi.org/10.1111/dom.13129

15 During MJ, Cao L, Zuzga DS, et al. Glucagon-like peptide-1 receptor is involved in learning and neuroprotection. Nat Med 2003;9:1173-9. https://doi.org/10.1038/nm919

16 Holscher C. Potential role of glucagon-like peptide-1 (GLP-1) in neuroprotection. CNS Drugs 2012;26:871-882. https://doi.org/10.2165/11635890-000000000-00000

17 Mattson MP, , Perry T, Greig NH. Learning from the gut. Nat Med 2003;9:1113-1115. https://doi.org/10.1038/ nm0903-1113 
18 Abbas T, Faivre E, Holscher C. Impairment of synaptic plasticity and memory formation in GLP-1 receptor KO mice: interaction between type 2 diabetes and Alzheimer's disease. Behav Brain Res 2009;205:265-271. https://doi. org/10.1016/j.bbr.2009.06.035

19 Holscher C. Central effects of GLP-1: new opportunities for treatments of neurodegenerative diseases. J Endocrinol 2014;221:T31-T41. https://doi.org/10.1530/ JOE-13-0221

20 Perry $\mathrm{T}$, Greig NH. The glucagon-like peptides: a double-edged therapeutic sword? Trends Pharmacol Sci 2003;24:377-383. https://doi.org/10.1016/ S0165-6147(03)00160-3

21 Huang $\mathrm{HJ}$, Chen $\mathrm{YH}$, Liang $\mathrm{KC}$, et al. Exendin-4 protected against cognitive dysfunction in hyperglycemic mice receiving an intrahippocampal lipopolysaccharide injection. PLoS One 2012;7:e39656. https://doi.org/10.1371/journal.pone.0039656

22 Perry T, Haughey NJ, Mattson MP, et al. Protection and reversal of excitotoxic neuronal damage by glucagon-like peptide-1 and exendin-4. J Pharmacol Exp Ther 2002;302:881-888. https://doi.org/10.1124/ jpet.102.037481

23 Cassano T, Serviddio G, Gaetani S, et al. Glutamatergic alterations and mitochondrial impairment in a murine model of Alzheimer disease. Neurobiol Aging 2012;33:1121 e112. https://doi.org/10.1016/j.neurobiolaging.2011.09.021

24 Grigoletto F, Zappala G, Anderson DW, et al. Norms for the mini-mental state examination in a healthy population. Neurology 1999;53:315-320. https://doi.org/10.1212/ wnl.53.2.315

25 Perry T, Lahiri DK, Sambamurti K, et al. Glucagon-like peptide-1 decreases endogenous amyloid-beta peptide (Abeta) levels and protects hippocampal neurons from death induced by Abeta and iron. J Neurosci Res 2003;72:603612. https://doi.org/10.1002/jnr.10611

26 Biessels GJ, Kamal A, Ramakers GM, et al. Place learning and hippocampal synaptic plasticity in streptozotocin-induced diabetic rats. Diabetes 1996;45:1259-1266. https://doi.org/10.2337/diabetes.45.9.1259
27 Bliss TVP, Collingridge GL. A synaptic model of memory: long-term potentiation in the hippocampus. Nature 1993;361:31-39. https://doi.org/10.1038/361031a0

28 Gardoni F, Kamal A, Bellone C, et al. Effects of streptozotocin-diabetes on the hippocampal NMDA receptor complex in rats. J Neurochemistry 2002;80:438-447. https://doi. org/10.1046/j.0022-3042.2001.00713.x

29 Baudry M, Massicotte G, Hauge S. Opposite effects of phospholipase A2 on [3H]AMPA binding in adult and neonatal membranes. Develop Brain Res 1991;61:265-267. https://doi.org/10.1016/0165-3806(91)90140-e

30 Romano AD, Greco E, Vendemiale G, et al. Bioenergetics and mitochondrial dysfunction in aging: recent insights for a therapeutical approach. Curr Pharm Des 2014;20:29782992. https://doi.org/10.2174/13816128113196660700

31 Sun X, Yao H, Douglas RM, et al. Insulin/PI3K signaling protects dentate neurons from oxygen-glucose deprivation in organotypic slice cultures. J Neurochemistry 2010;112:377388. https://doi.org/10.1111/j.1471-4159.2009.06450.x

32 Chen S, Sun J, Zhao G, et al. Liraglutide improves water maze learning and memory performance while reduces hyperphosphorylation of tau and neurofilaments in APP/PS1/ Tau triple transgenic mice. Neurochem Res 2017;42:23262335. https://doi.org/10.1007/s11064-017-2250-8

33 Vadini F, Simeone PG, Boccatonda A, et al. Liraglutide improves memory in obese patients with prediabetes or early type 2 diabetes: a randomized, controlled study. Int J Obes (Lond) 2020;44:1254-1263. https://doi.org/10.1038/ s41366-020-0535-5

34 Anu J, Peeyush Kumar T, Nandhu MS, et al. Enhanced NMDAR1, NMDA2B and mGlu5 receptors gene expression in the cerebellum of insulin induced hypoglycaemic and streptozotocin induced diabetic rats. Eur J Pharmacol 2010;630:61-68. https://doi.org/10.1016/j. ejphar.2009.12.024

35 Nakai T, Nagai T, Tanaka M, et al. Girdin phosphorylation is crucial for synaptic plasticity and memory: a potential role in the interaction of BDNF/TrkB/Akt signaling with NMDA receptor. J Neurosci 2014;34:14995-5008. https://doi. org/10.1523/JNEUROSCI.2228-14.2014 